\title{
Hand function and quality of life before and after fasciectomy for Dupuytren contracture
}

Christina Engstrand, Barbro Krevers, Göran Nylander and Joanna Kvist

\section{Linköping University Post Print}

\section{Tweet}

N.B.: When citing this work, cite the original article.

Original Publication:

Christina Engstrand, Barbro Krevers, Göran Nylander and Joanna Kvist, Hand function and quality of life before and after fasciectomy for Dupuytren contracture, 2014, Journal of Hand Surgery-American Volume, (39), 7, 1333-1343.

http://dx.doi.org/10.1016/j.jhsa.2014.04.029

Copyright: WB Saunders

http://www.elsevier.com/

Postprint available at: Linköping University Electronic Press

http://urn.kb.se/resolve?urn=urn:nbn:se:liu:diva-109387 
Hand function and quality of life before and after

Fasciectomy for Dupuytren contracture

Key words: Dupuytren contracture, surgical treatment, range of motion, satisfaction, occupational therapy

\section{Abstract}

\section{Purpose}

To describe changes in joint motion, sensibility, and scar pliability and to investigate the patients' expectations, self-reported recovery, and satisfaction with hand function, disability, and quality of life after surgery and hand therapy for Dupuytren disease.

\section{Methods}

This prospective cohort study collected measurements before surgery and 3, 6, and 12 months after surgery and hand therapy. Ninety patients with total active extension deficits of 60 degrees or more from Dupuytren contracture were included. Outcomes measures were range of motion, sensibility, scar pliability, self-reported outcomes on expectations, recovery, and satisfaction with hand function, Disabilities of the Arm, Shoulder, and Hand scores, safety and social issues of hand function, physical activity habits, and quality of life with the Euroqol.

\section{Results}

The extension deficit decreased, and there was a transient decrease in active finger flexion during the first year after surgery. Sensibility remained unaffected. Generally, patients with surgery on multiple fingers had worse scar pliability. The majority of the patients had their expectations met, and at 6 months 32\% considered hand function as fully recovered, and $73 \%$ were satisfied with their hand function. Fear of hurting the hand and worry about not trusting the hand function were of greatest concern among safety and social issues. The Disability of the Arm, Shoulder and Hand score and the Euroqol improved over time. 


\section{Conclusion}

After surgery and hand therapy, disability decreased independent of single or multiple operated fingers. The total active finger extension improved enough for the patients to reach a functional range of motion despite an impairment of active finger flexion still present 12 months after treatment.

Level of evidence:

Therapeutic, level IV. 


\section{Introduction}

Dupuytren disease (DD) is a benign connective tissue disorder with unknown etiology. It affects the palmar fascia of the hand, leading to progressive finger joint contractures (1). A common treatment is surgical fasciectomy, but non-surgical treatment options exist. The treatment does not cure the disease, and recurrence is common $(2,3)$. Possible adverse effects of surgery are vascular or nerve damage, delayed wound healing, scar problems, infection, swelling, complex regional pain syndrome, and loss of finger flexion (4-6). Some surgeons recommend postoperative hand therapy (7-9), and according to clinical experience, recovery after surgery takes in general 3 to 6 months (8).

Previous research has focused on outcomes related to surgical techniques, decrease of extension deficit, or disease recurrence $(3,10-12)$ and show larger improvement of the extension deficit in the metacarpophalangeal (MCP) joint than in the proximal interphalangeal (PIP) joint (10). Further, a more severe degree of contracture before surgery or contracture of the PIP joint has been associated with residual contracture after surgery $(10,13,14)$. Though reduced finger flexion is a potential complication (4), few studies report the impact of surgery on finger flexion. Descriptions of finger flexion after surgery vary from all patients regaining finger flexion within 2 weeks (15) to flexion deficits present 6 weeks postoperative (16) to no patients achieving restoration of full range of motion (ROM) (17). Benefits in ROM over time have been reported occasionally for isolated joints (18), and some studies report improvement in hand function after surgery measured by the Sollerman grip function test $(13,19)$. Few studies report assessment of sensibility before and after surgery (20), though 1 study using the Semmes-Weinstein monofilaments report diminished light touch and protective sensation after surgery (17). Scar contracture is another potential complication after surgery $(5,6)$ and should be distinguished from recurrence, i.e. the development of new DD tissue in the 
operated area (1). Despite possible drawbacks of surgery, several studies report high overall patient satisfaction or satisfaction with the procedure $(15,17,20-24)$. After fasciectomy, patients also report improved quality of life (25).

The aim of our study was to describe changes over time in finger joint motion, sensibility, and scar pliability and to investigate the patients' expectations, self-reported recovery, and satisfaction with hand function, disability, and quality of life after surgery and hand therapy for DD.

We hypothesized that there would be a negative effect of surgery on finger flexion and sensibility and that self-reported recovery of hand function would take 3-6 months. We expected the extension deficit of the operated finger to decrease enough to reach a ROM needed for performance of daily activities.

\section{Materials and methods}

The study design was a prospective cohort study with routine evaluations at 4 consistent time points: immediately before surgery and at 3, 6, and 12 months after surgery and hand therapy.

\section{Patients}

We recruited patients with DD consecutively as they were scheduled for fasciectomy from a center for hand surgery in Sweden. Inclusion criteria were an extension deficit of 60 degrees or more in digit II-V in an isolated finger joint or as the sum of the extension deficits of the MCP, PIP, and distal interphalangeal (DIP) joints in the affected finger. Of 123 available patients, 19 did not meet the inclusion criteria, and 10 declined participation. Ninety-four patients gave informed consent. We excluded 4 patients due to incomplete measurements, 
leaving 90 patients to participate in the study (Figure 1), 77 of whom attended all follow-ups. Of the 90 patients included in the study, 70 had surgery in 1 finger, 16 had surgery in 2 fingers, and 4 patients had surgery in 3 fingers. Seven patients had contractures only in the MCP joint, 9 patients only in the PIP joint, and 74 in both MCP and PIP joint (Table 1). Twenty patients had previous upper extremity disease not located to the hand or finger, for example neck/shoulder pain $(n=12)$, fractures $(n=2)$, osteoarthritis $(n=2)$, and rheumatic disease $(n=1)$.

\section{Intervention}

The surgical intervention followed a standard protocol of fasciectomy with straight-line incisions, removal of the pathological tissue, and closure with z-plasties. If there was a shortage of skin or bad skin quality, the surgeon used an open palm technique $(n=8)$. If there was a residual extension deficit of $25-30^{\circ}$ left in the PIP joint after the fasciectomy, the surgeon removed the volar plate of the PIP joint $(n=9)$. After surgery, the hand was casted. We used a standard postoperative treatment previously described (26) regardless of the extent of surgery. One week after surgery, the occupational therapist (OT) removed the cast. All patients started active exercises with both isolated joint motions and composite flexion and extension. They received a volar orthosis with the wrist in $10-20^{\circ}$ extension, the $\mathrm{MCP}$ joint in $10-20^{\circ}$ flexion, and the interphalangeal joints in maximum extension without tensioning the wounds. Beginning 1 week after surgery, the patient used the orthosis 24 hours a day with removal only during exercise. A week later, the patient used the orthosis only at night. Nighttime splinting continued for 3-6 months. Ninety-eight percent used their orthosis at 3 months after surgery and $37 \%$ were still using it at 6 months. Some patients needed further postoperative hand therapy beyond the therapy described above (Table 2). 


\section{Data collection}

Two OTs, not involved in the postoperative treatment, were responsible for measurements at all follow-ups. The same OT followed each patient with the exception of 5 patients living further away from the hospital, where local OTs specially trained for the study performed the follow-up measurements (24). The OTs systematically collected information about postoperative hand therapy given for swelling, pain, ROM, splinting, and scars.

\section{Outcomes}

We assessed active ROM with extension and flexion only. We measured maximum active extension and flexion in the MCP, PIP, and DIP joint according to guidelines (27). We summed maximum active extension and flexion for individual joints for each operated finger giving the total active extension deficit and total active flexion. We calculated total active ROM as the total active flexion minus the total active extension deficit. We noted hyperextension in the DIP joint but converted it to 0 degrees in the analysis as this could underestimate the total active extension deficit. We compared participants' total ROM with $165^{\circ}$ total ROM, representing the minimum functional ROM needed for performance of 11 common daily activities and with $290^{\circ}$ representing normal ROM (28).

Sensibility of the fingertip of the operated finger was measured with the Semmes-Weinstein monofilament (29) with 5 filaments ranging from $1=$ normal sensibility (2.83 filament) to 5=deep pressure only (6.65 filament).

Scar pliability was assessed on all follow-up occasions by visual inspection and palpation of the scar tissue. The scar tissue was graded on a subscale from the Vancouver Scar Scale: 1=normal (normal skin), 2=supple (flexible scar with minimal resistance), 3=yielding (scar 
giving way to pressure), 4=firm (scar inflexible, not easily moved, resistant to manual pressure), $5=$ ropes (rope-like tissue that blanches with extension of scar), $6=$ contracture (permanent shortening of scar producing deformity/distortion) (30). The patient extended the fingers during the assessment.

Self-reported outcomes consisted of:

- Expectations about and recovery of hand function (global index): 7-point scale ranging from 1equaling fully recovered to 7 equaling much worse (31)

- Satisfaction with current hand function (global index): 7-point scale ranging from 1 equaling delighted to 7 equaling terrible (32)

- The Disabilities of the Arm, Shoulder and Hand Questionnaire (DASH), Swedish version: 30 -item disability/symptoms scale giving a score ranging from 0 equaling no disability to 100 equaling severest disability $(33,34)$

- Safety and social issues regarding hand function:

1. worry about not trusting the hand function

2. need to take special precautions due to hand function

3. fear of hurting the hand

4. concern about the appearance of the hand

5. avoiding use of the hand in social contexts

Response options ranged from 1 equaling to a large degree to 10 equaling not at all

- Present physical activity habits: 6-point scale ranging from 1 equaling hardly any physical activity to 6 equaling hard exercise several times a week (35).

- The Euroqol (EQ-5D), Swedish version: a descriptive profile of 5 areas which is converted into a summary index ranging from 1 equaling full health to -0.594 equaling worst imaginable health state and a vertical visual analogue scale (VAS) where overall 
health is rated 100 equaling best imaginable health state and 0 equaling worst imaginable health state"(36).

\section{Statistical analysis}

We estimated the necessary sample size to 58 patients based on a change of $15^{\circ}$ in extension deficit with a standard deviation of $30^{\circ}$ and a power of $90 \%$. Based on the results of finger flexion with a change of $10^{\circ}$ and $\operatorname{SD} 23^{\circ}$, the power of the study exceeded $90 \%$. To handle multiple observations in the analysis, we divided the patients into 2 subgroups consisting of patients with surgery on 1 finger and surgery on multiple ( 2 or 3$)$ fingers $(37,38)$. For patients with surgery on multiple fingers we calculated an average (37) for ROM and sensibility outcomes. We performed the analysis on the whole group and on subgroups. We used descriptive statistics for demographic data and sample characteristics, and Fisher exact and ttests for identifying differences between subgroups regarding sample characteristics. We summed and averaged rating of safety issues (question 1-3) and social issues (question 4-5) before surgery and compared them with Wilcoxon signed rank test. For ROM, the DASH, and EQ-5D we used a 1-way full-factorial repeated measures analysis of variance with surgery on 1 or multiple fingers as a between-subjects factor. In addition, we performed a single contrast analysis using the preoperative measure as a reference. For non-parametric variables, we used the Friedman test and Wilcoxon signed rank test with Bonferroni correction for identifying difference between follow-up occasion, and the Kruskal Wallis Test for analysis of differences between subgroups. We calculated the relative risk (risk-ratio) for having scar pliability rated as firm, ropes, or contracture depending on the number of operated fingers. We considered a $P$-value of $\leq 0.05$ as significant.

The regional ethical review board in Linkoping, Sweden approved the study. 


\section{Results}

\section{ROM, sensibility, scar pliability}

Figures 2-4 show ROM outcomes. The total active extension deficit reduction was significant at 3 months and remained stable over time. Total finger flexion was significantly impaired at 3 months and was still slightly impaired at 12 months compared to before surgery. At 12 months, flexion in the MCP joint had recovered while PIP joint flexion still was slightly impaired. Number of operated fingers did not affect ROM outcome, i.e. ROM did not differ between subgroups, and the course of change over time in ROM was similar for both groups. Eighty-seven percent of the patients reached a functional $\operatorname{ROM}\left(\geq 165^{\circ}\right)$ at 12 months while no patient reached normal $\mathrm{ROM}\left(\geq 290^{\circ}\right)$. Sensibility was unchanged over time and did not differ between subgroups (Fig 5). Patients with surgery on multiple fingers had an increased risk of having worse scar pliability (firm, ropes, or contracture) (Table 3).

\section{Expectations, recovery and satisfaction with hand function}

No difference was seen between expectations from before surgery and self-reported recovery at 12 months $(P=0.077)$. Self-reported recovery of hand function improved until 6 months $(P<0.001)$ with no further changes to twelve months (Table 3$)$. The subgroups did not differ in expectations, recovery, or satisfaction with hand function.

\section{Disability and quality of life}

Patients with multiple operated fingers had significantly higher DASH scores before surgery and on all follow-up occasions with no interaction effect in change over time between the DASH and number of operated fingers (Fig 6). There was no interaction effect between number of operated fingers and the EQ-5D VAS while the EQ-5D index showed temporarily lower scores at 3 and 6 months for patients with surgery on multiple fingers (Table 4). Before surgery, safety issues of hand function were a significantly larger problem than social issues 
but ratings on all 5 questions improved over time (Fig 7). Before surgery, patients scheduled for surgery on multiple fingers had significantly worse scores on "need to take special precautions due to hand function" and "fear of hurting the hand" $(P \leq .029)$, and at 12 months this was still the case on "need to take special precautions due to hand function" $(P=.028)$. Physical activity habits were unchanged over time $(P=.074)$ with the majority performing light or moderate physical exercise.

\section{Discussion}

The present study showed that the total active extension deficit decreased after fasciectomy and hand therapy and recovery of finger flexion continued for at least 12 months with the PIP joint recovering more slowly. The majority of the patients had their expectations for recovery of hand function met and were satisfied with their hand function at 12 months. At that time, the majority of the patients had reached a functional but not normal ROM. Fear of hurting the hand and worry about not trusting the hand function were of greater concern than other safety or social issues. The DASH and EQ-5D VAS improved over time, and the scores at 12 months were close to the general population.

The improvement in total active extension deficit during the first year after surgery and hand therapy was in line with previous research (10). The present study confirmed our assumption of a negative effect on active finger flexion. We did not measure passive ROM, which could have helped to differentiate between contracture and motion lag. However, from the patients' view, the compromised function is what matters regardless of its cause (12). At 12 months, the majority had regained sufficient flexion to allow a functional ROM, i.e. exceeding $165^{\circ}$. Reaching full ROM might not be a reasonable goal after surgery; instead, the overall goal should be to reach a level of improvement that allows for acceptable hand function. An 
important feature of hand function is the combination of strength, stability, sensibility, and ROM (39). We did not assess strength or restrictions in abduction/adduction due to difficulties with baseline measurement associated with severe contractures.

We assumed that there would be a negative effect on sensibility (17), but the present study did not confirm this. The proportion of patients with diminished protective sensation was lower than previously reported data $(17,40)$. Before surgery and at 12 months, the majority of the patients had diminished light touch, which might not have a functional impact and can be unnoticed by the individual (29). Further, the ability to detect monofilament 2.83 (normal sensibility) may be lost due to aging (40).

To determine whether the patient reached an acceptable level of hand function, it is important to look beyond traditional measures of hand function (ROM, sensation etc.) and to include the patient's perspective. In the present study, a majority of the patients rated their hand function as much better or fully recovered at 6 months. Although not all patients had regained finger flexion at that time, we found no further improvement in self-reported recovery of hand function after 6 months. Previous research has associated satisfaction with fulfillment of expectations (41), and in the present study most patients had their expectations fulfilled. However, the patients with previous experience of hand surgery might have a preunderstanding that influenced their expectations and satisfaction. Patients can also have other influencing previous experiences e.g. through others or internet for example. This was not investigated specifically as it was beyond the scope of the present study. The questions regarding safety and social issues of hand function represent emotional aspects, and the effect showed in this study with reduced fear or worry about using the hand is an important aspect of attaining an acceptable hand function. 
When multiple digits are involved, natatory cords commonly influence the adjacent digit. This can be 1 explanation for the higher DASH scores among patients with surgery on multiple fingers. The DASH scores showed a parallel decrease between patients with surgery on 1 or multiple fingers, where the latter reached the level of a clinical important change $(42,43)$. Patients with surgery on 1 finger had low baseline scores that were within the range of the normal value of DASH score (44), indicating that the DASH is not sensitive enough because a ceiling effect occurs and it might underestimate their disability. The EQ-5D VAS improved over time, but the levels of the EQ-5D VAS and index were consistently high and in line with values in the general Swedish population (45).

Our study had several limitations. There was diversity in the study sample due to the inclusion criteria. An extension deficit of a single PIP joint might adversely influence hand function differently (19) than the same cumulative amount of contracture in 3 joints. Further, we did not consider severity or location of the preoperative contracture, and having contracture only in the MCP joint might lead to faster recovery or a better outcome. Likewise, we could not make conclusion about how release of the volar plate of the PIP joint influenced the outcome. Although Misra et al. (2007) showed no impact of PIP joint release on the outcome (46), these patients might have had a worse prognosis. The present study did not have enough power for considering these aspects in the analysis. The use of the scar pliability subscale was another potential weakness due to the subjective assessment of the scar $(47,48)$. It could be difficult to differentiate between contractures associated with wound healing versus residual/progression of the disease. To increase reliability, the rating scale had a short statement giving guidance, and the rating OTs discussed the rating scale before the study 
started. We created the questions about safety and social issues, and although they have not been used before, they cover aspects shown to be important for patients with DD (49). 


\section{References}

1. Hindocha S, Stanley J K, Watson S, et al. Dupuytrens diathesis revised: evaluation of prognostic indicators for risk of disease recurrence. J Hand Surg Am. 2006;31:16261634.

2. Desai S S, Hentz V R. The treatment of Dupuytren disease. J Hand Surg Am. 2011;36(5):936-942.

3. Werker P M, Pess G M, van Rijssen A L, et al. Correction of contracture and recurrence rates of Dupuytren contracture following invasive treatment: the importance of clear definitions. J Hand Surg Am. 2012;37:2095-2105.

4. Denkler K. Surgical complications associated with fasciectomy for dupuytren's disease: a 20-year review of the English literature. Eplasty. 2010;10:e15.

5. Prosser R, Conolly W B. Complications following surgical treatment for Dupuytren's contracture. J Hand Ther. 1996;9(4):344-348.

6. Evans R B, Dell P C, Fiolkowski P. A clinical report of the effect of mechanical stress on functional results after fasciectomy for Dupuytren's contracture. $J$ Hand Ther. 2002;15(4):331-339.

7. Shih B, Bayat A. Scientific understanding and clinical management of Dupuytren disease. Nat Rev Rheumatol. 2010;6:715-726.

8. Birks M, Bhalla A. Dupuytren's disease. Surgery. 2013;31(4):177-180.

9. Au-Yong I, Wildin C, Page. A review of common practice in Dupuytren Surgery. Techniques in Hand and Upper Extremity Surgery. 2005;9:178-187.

10. Crean S M, Gerber R A, Hellio Le Graverand M P, et al. The efficacy and safety of fasciectomy and fasciotomy for Dupuytren's contracture in European patients: a structured review of published studies. J Hand Surg Eur. 2011;36:396-407.

11. Kan H J, Verrijp F W, Huisstede B M, et al. The consequences of different definitions for recurrence of Dupuytren's disease. Journal of plastic, reconstructive \& aesthetic surgery: JPRAS. 2013;66(1):95-103.

12. Dias J J, Braybrooke J. Dupuytren's contracture: an audit of the outcomes of surgery. $J$ Hand Surg Eur. 2006;31:514-521.

13. Sinha R, Cresswell T, Mason R, et al. Functional benefit of Dupuytren's surgery. $J$ Hand Surg Eur. 2002;27:378-381.

14. Donaldson O W, Pearson D, Reynolds R, et al. The association between intraoperative correction of Dupuytren's disease and residual postoperative contracture. J Hand Surg Eur. 2010;35:220-223.

15. Degreef I, Tejpar S, De Smet L. Improved postoperative outcome of segmental fasciectomy in Dupuytren disease by insertion of an absorbable cellulose implant. Journal of plastic surgery and hand surgery. 2011;45(3):157-64.

16. van Rijssen A L, Gerbrandy F S, Ter Linden H, et al. A comparison of the direct outcomes of percutaneous needle fasciotomy and limited fasciectomy for Dupuytren's disease: a 6-week follow-up study. J Hand Surg Am. 2006;31:717-725.

17. Roush T, Stern P. Results following surgery for recurrent Dupuytren's disease. J Hand Surg Am. 2000;25:291-296.

18. Ullah A S, Dias J J, Bhowal B. Does a 'firebreak' full-thickness skin graft prevent recurrence after surgery for Dupuytren's contracture?: a prospective, randomised trial. J Bone Joint Surg Br. 2009;91(3):374-378.

19. Draviaraj K P, Chakrabarti I Functional outcome after surgery for Dupuytren's contracture: a prospective study. J Hand Surg Am. 2004;29:804-808. 
20. Ball C, Pratt A L, Nanchahal J. Optimal functional outcome measures for assessing treatment for Dupuytren's disease: a systematic review and recommendations for future practice. BMC musculoskeletal disorders. 2013;14:131.

21. Cheng H S, Hung L K, Tse W L, et al. Needle aponeurotomy for Dupuytren's contracture. Journal of orthopaedic surgery. 2008;16(1):88-90.

22. Beaudreuil J, Lermusiaux J L, Teyssedou J P, et al. Multi-needle aponeurotomy for advanced Dupuytren's disease: preliminary results of safety and efficacy (MNA 1 study). Joint, bone, spine: revue du rhumatisme. 2011;78(6):625-628.

23 Toppi J T, Trompf L, Smoll N R, et al. Dupuytren's contracture: an analysis of outcomes of percutaneous needle fasciotomy versus open fasciectomy. ANZ journal of surgery. 2014, E-pub ahead of print.

24 Vollbach F H, Walle L, Fansa H. Dupuytren's disease - patient satisfaction and functional results one year after partial fasciectomy and injection of collagenase. Handchirurgie, Mikrochirurgie, plastische Chirurgie. 2013;45(5):258-264.

25. Thoma A, Kaur M, Ignacy T A, et al. Health Related Quality of Life in Patients undergoing Palmar Fasciectomy for Dupuytren's Disease. Plastic and reconstructive surgery. 2014. E-pub ahead of print.

26. Engstrand C, Boren L, Liedberg G M. Evaluation of activity limitation and digital extension in Dupuytren's contracture three months after fasciectomy and hand therapy interventions. J Hand Ther. 2009;22:21-26.

27. Engstrand C, Krevers B, Kvist J. Interrater Reliability in Finger Joint Goniometer Measurement in Dupuytren's Disease. Am J Occ Ther. 2012;66(1):98-103.

28. Hume M, Gellman H, McKellop H, et al. Functional range of motion of the joints of the hand. J Hand Surg Am. 1990;15:240-243.

29. Bell-Krotoski J A. Sensibility testing with the Semmes-Weinstein Monofilaments. In: Hunter JM, Mackin EJ, Callahan AD, ed. Rehabilitation of the Hand. St Louis: The Mosby Company: 2002: 194-213.

30. Sullivan T, Smith J, Kermode J, et al. Rating the burn scar. J Burn Care Rehabil. 1990;11(3):256-260.

31. Yalcin I, Bump R C. Validation of two global impression questionnaires for incontinence. Am J Obstet Gynecol. 2003;189(1):98-101.

32. Cherkin D. Predicting poor outcomes for back pain seen in primary care using patients' own criteria. Spine. 1996;21(24):2900-2907.

33. Atroshi I, Gummesson C, Andersson B, et al. The disabilities of the arm, shoulder and hand (DASH) outcome questionnaire: reliability and validity of the Swedish version evaluated in 176 patients. Acta Orthop Scand. 2000;71(6):613-618.

34. Gummesson C, Atroshi I, Ekdahl C. The disabilities of the arm, shoulder and hand (DASH) outcome questionnaire: longitudinal construct validity and measuring selfrated health change after surgery. BMC Musculoskelet Disord. 2003;4:11.

35. Grimby G. Physical-Activity and Muscle Training in the Elderly. Acta Med Scand. 1986:233-237.

36. Oemar M, Oppe M. EQ-5D-3L user guide. Basic information on how to use the EQ5D-3L instrument. Rotterdam: EuroQol Group; 2013.

37. Altman D G, Bland J M. Statistics notes. Units of analysis. BMJ. 1997;314(7098):1874.

38. Bryant D, Havey T C, Roberts R, et al. How many patients? How many limbs? Analysis of patients or limbs in the orthopaedic literature: a systematic review. J Bone Joint surg Am. 2006;88(1):41-45.

39. Watt A J, Chang J. Functional reconstruction of the hand: the stiff joint. Clin Plast Surg. 2011;38(4):577-589. 
40. Desrosiers J, Hebert R, Bravo G, et al. Hand sensibility of healthy older people. $J$ Am Ger Soc. 1996;44(8):974-978.

41. Conner-Spady B L, Sanmartin C, Johnston G H, et al. The importance of patient expectations as a determinant of satisfaction with waiting times for hip and knee replacement surgery. Health policy. 2011;101(3):245-252.

42. Beaton D E, Katz J N, Fossel A H, et al. Measuring the whole or the parts? Validity, reliability, and responsiveness of the Disabilities of the Arm, Shoulder and Hand outcome measure in different regions of the upper extremity. $J$ Hand Ther. 2001;14(2):128-146.

43. Beaton D E, Davis A M, Hudak P, et al. The DASH (Disabilities of the Arm, Shoulder and Hand) Outcome Measure: What do we know about it now? J Hand Ther. 2001;6(4):109-118.

44. Hunsaker F G, Cioffi D A, Amadio P C, et al. The American academy of orthopaedic surgeons outcomes instruments: normative values from the general population. $J$ Bone Joint Surg Am. 2002;84-A(2):208-215.

45. Szende A, Williams A, eds. Measuring self-reported population health: an international perspective based on EQ-5D. 2004, EuroQolGroup.

46. Misra A, Jain A, Ghazanfar R, et al. Predicting the outcome of surgery for the proximal interphalangeal joint in Dupuytren's disease. J Hand Surg Am. 2007;32:240245.

47. Roques C, Teot L. A critical analysis of measurements used to assess and manage scars. Int J Low Extrem Wounds. 2007;6(4):249-253.

48. Fearmonti R, Bond J, Erdmann D, et al. A review of scar scales and scar measuring devices. Eplasty. 2010;10:e43.

49. Pratt A L, Byrne G. The lived experience of Dupuytren's disease of the hand. J Clin Nurs. 2009;18(12):1793-1802. 


\section{Figures:}

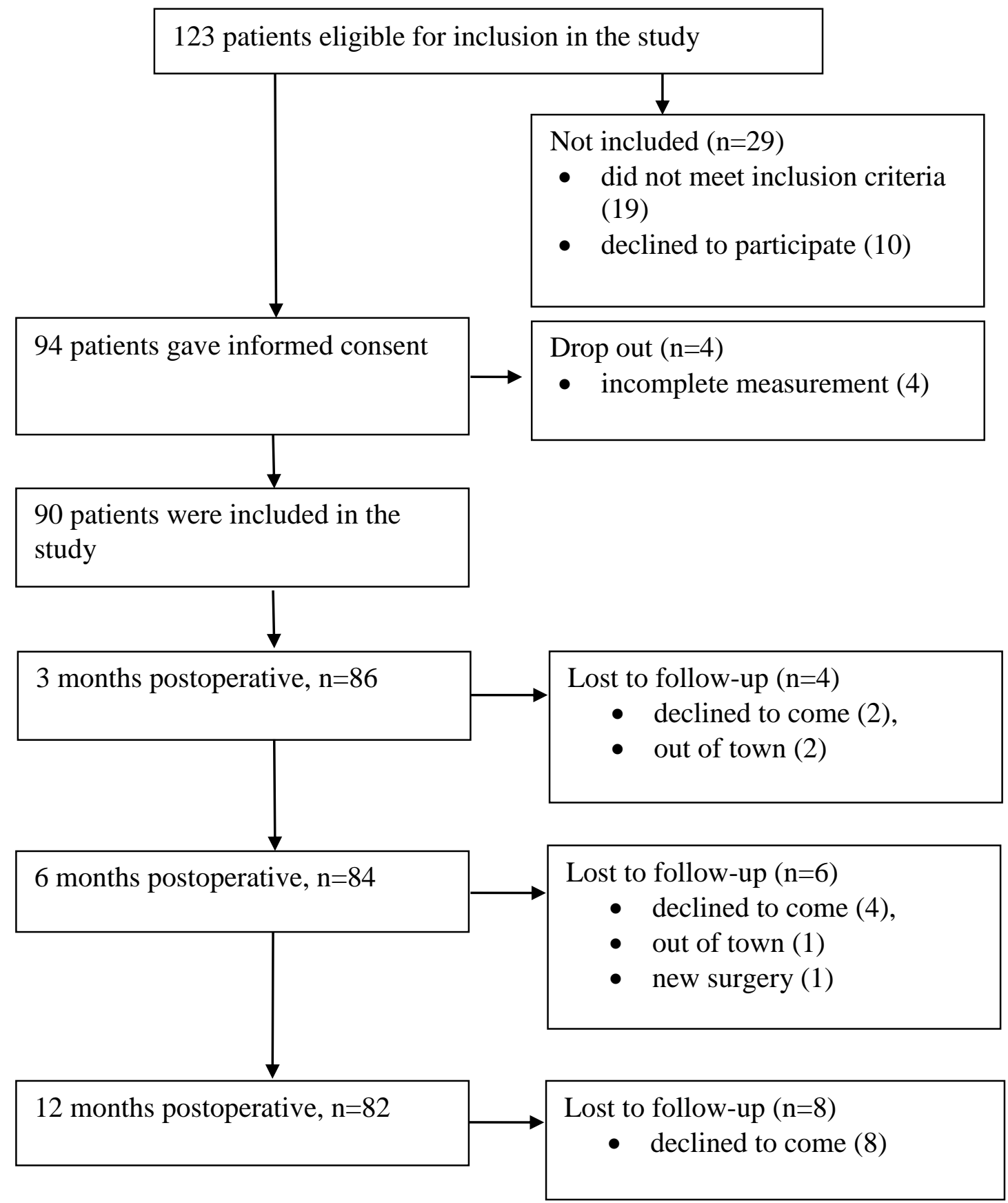

Figure 1. Flowchart on participants and dropouts in the study. Measurements on all occasions; ROM, sensibility and self-reported outcomes. Measurement on follow-up occasions; assessment of scar pliability. 

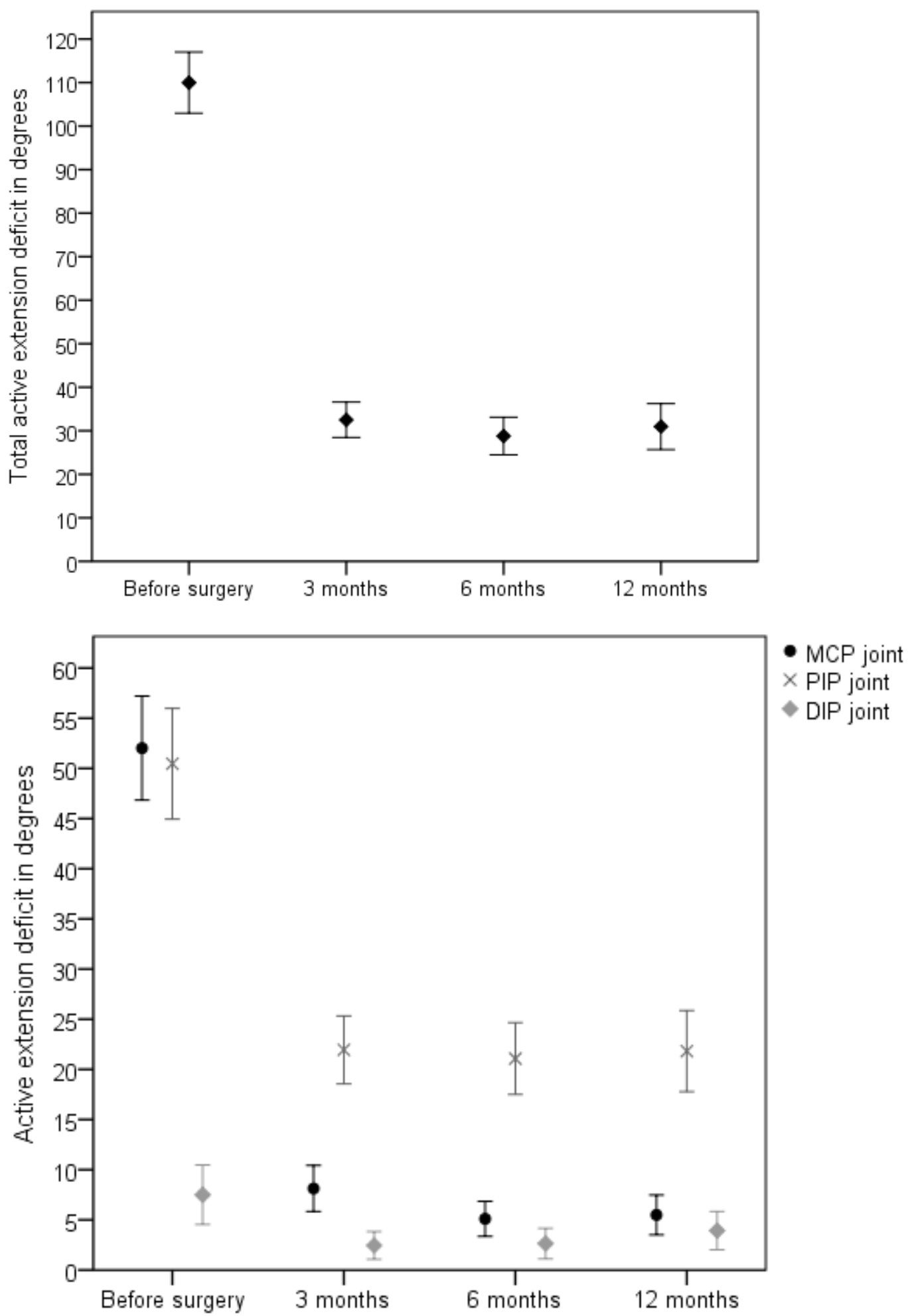

Figure 2. In figure 2A: Total active extension deficit (TAE) in the whole finger at different time points, significantly reduced at 3 months $(F(1,75)=506.70, P<.001)$. In figure 2B: Active extension deficit of isolated finger joints (MCP, PIP, and DIP) at different time points. Number of patients at each time point: before surgery $(n=90), 3$ months $(n=86), 6$ months $(n=84)$ and 12 months after surgery $(n=82)$. Data presented as mean degrees and $95 \%$ confidence intervals $(\mathrm{CI})$. 

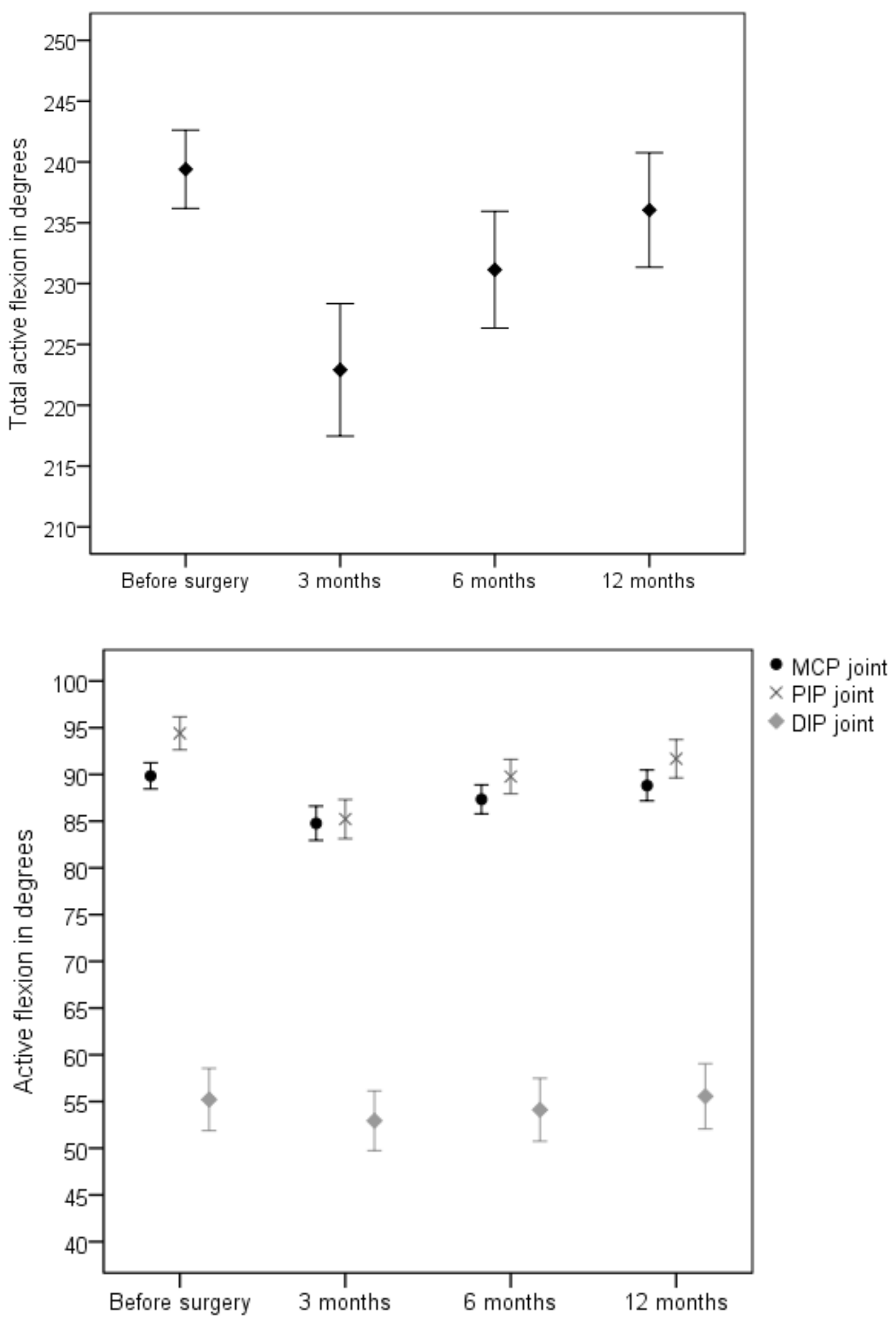

Figure 3. In figure 3A: Total active flexion (TAF) in the whole finger at different time points, significantly impaired at 3 months $(\mathrm{F}(1,75)=32.74, P<.001)$ and at 12 months $(\mathrm{F}(1,75)$ $=5.33, P=0.024)$ compared to before surgery. In figure 3B: Maximum active flexion of isolated finger joints (MCP, PIP and DIP) at different time points. PIP joint flexion still impaired at 12 months $(F(1,76)=4.99, P=0.028)$. Number of patients at each time point: 
before surgery $(n=90), 3$ months $(n=86), 6$ months $(n=84)$ and 12 months after surgery $(n=82)$. Data presented as mean degrees and $95 \%$ confidence intervals (CI).

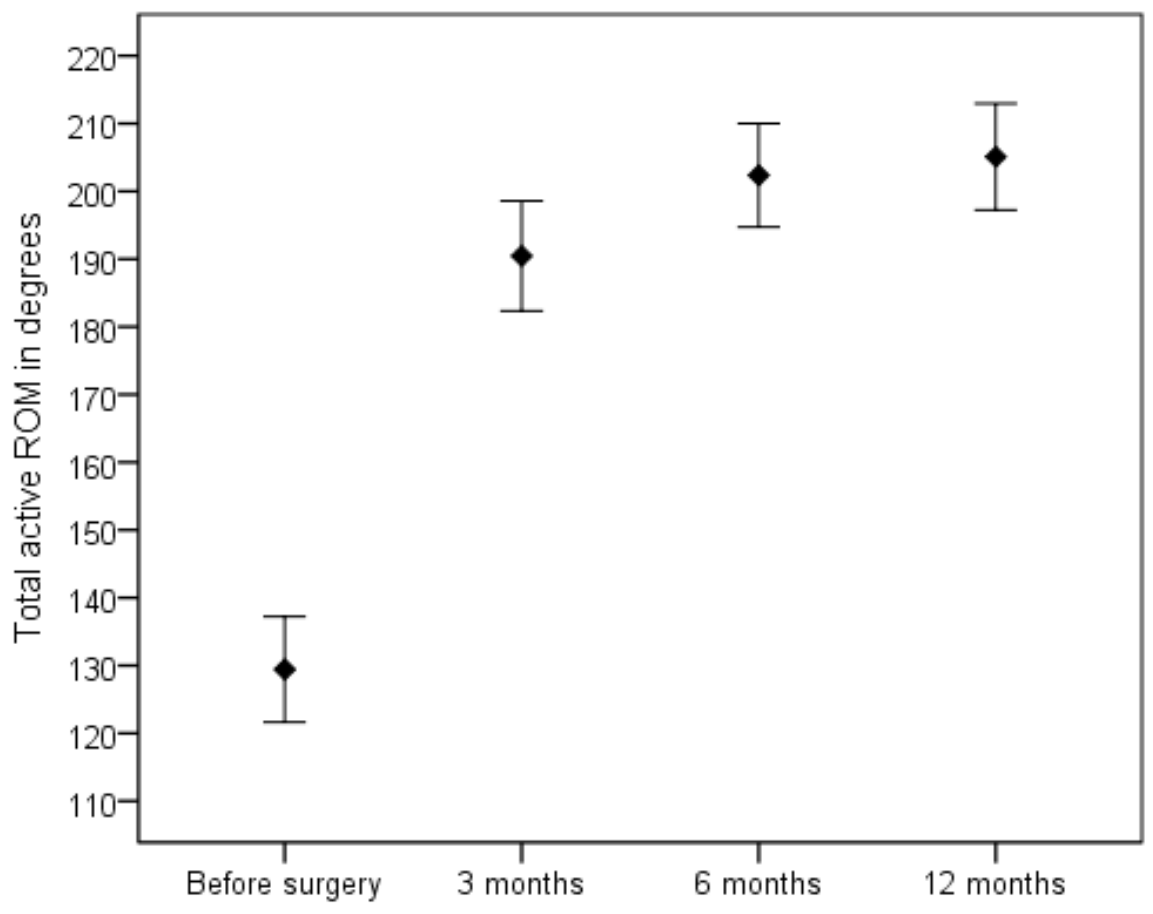

Figure 4. Total active ROM in the whole finger at different time points. Number of patients at each time point: before surgery $(n=90), 3$ months $(n=86), 6$ months $(n=84)$ and 12 months after surgery $(n=82)$. Data presented as mean degrees and $95 \%$ confidence intervals $(\mathrm{CI})$. 


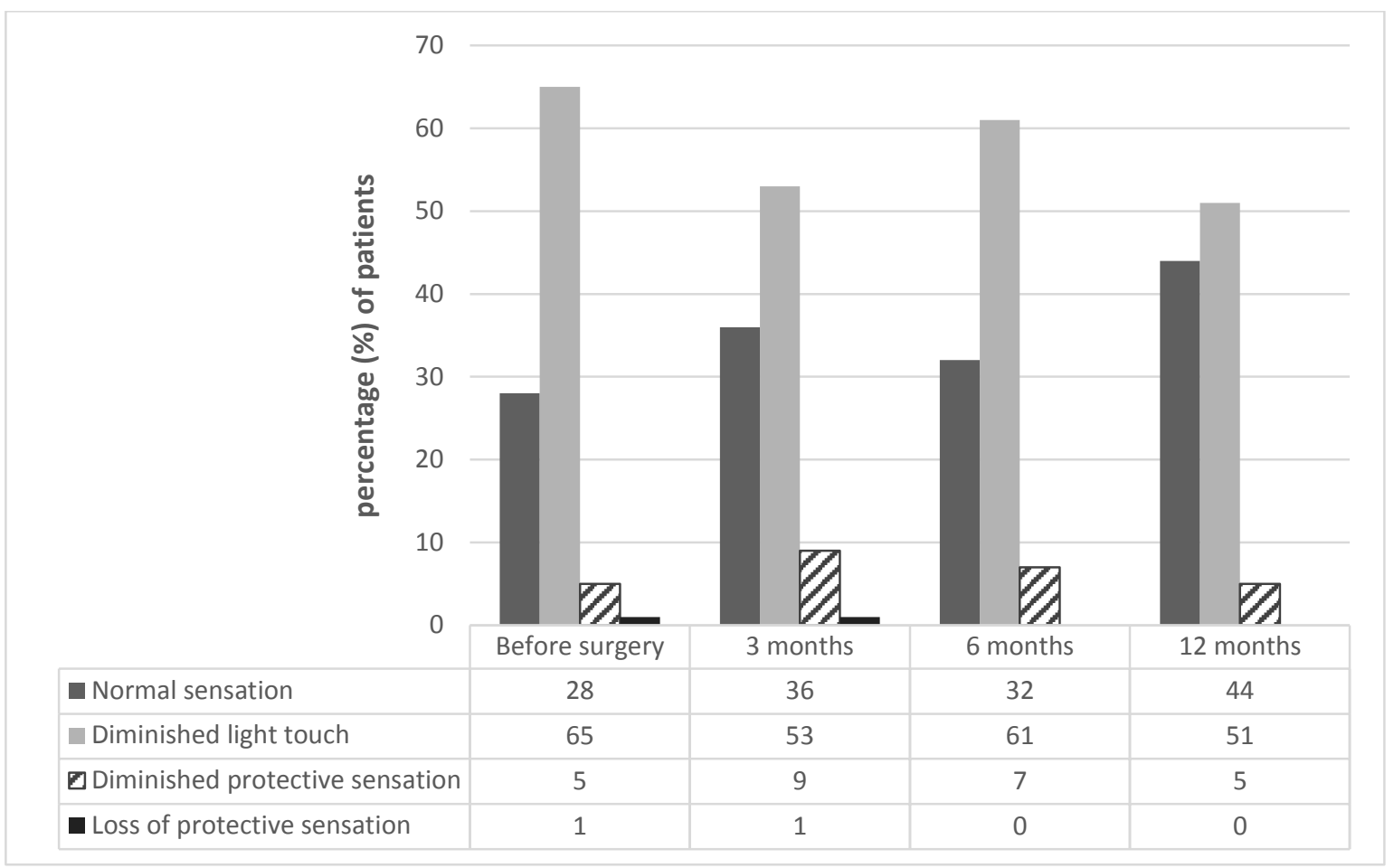

Figure 5. Outcomes on sensibility measured with Semmes-Weinstein monofilament for the whole group at different time points $(\mathrm{n}=75)(P=.056)$. Data presented as proportions (percentage) of patients with normal sensation, diminished light touch, diminished protective sensation or loss of protective sensation.

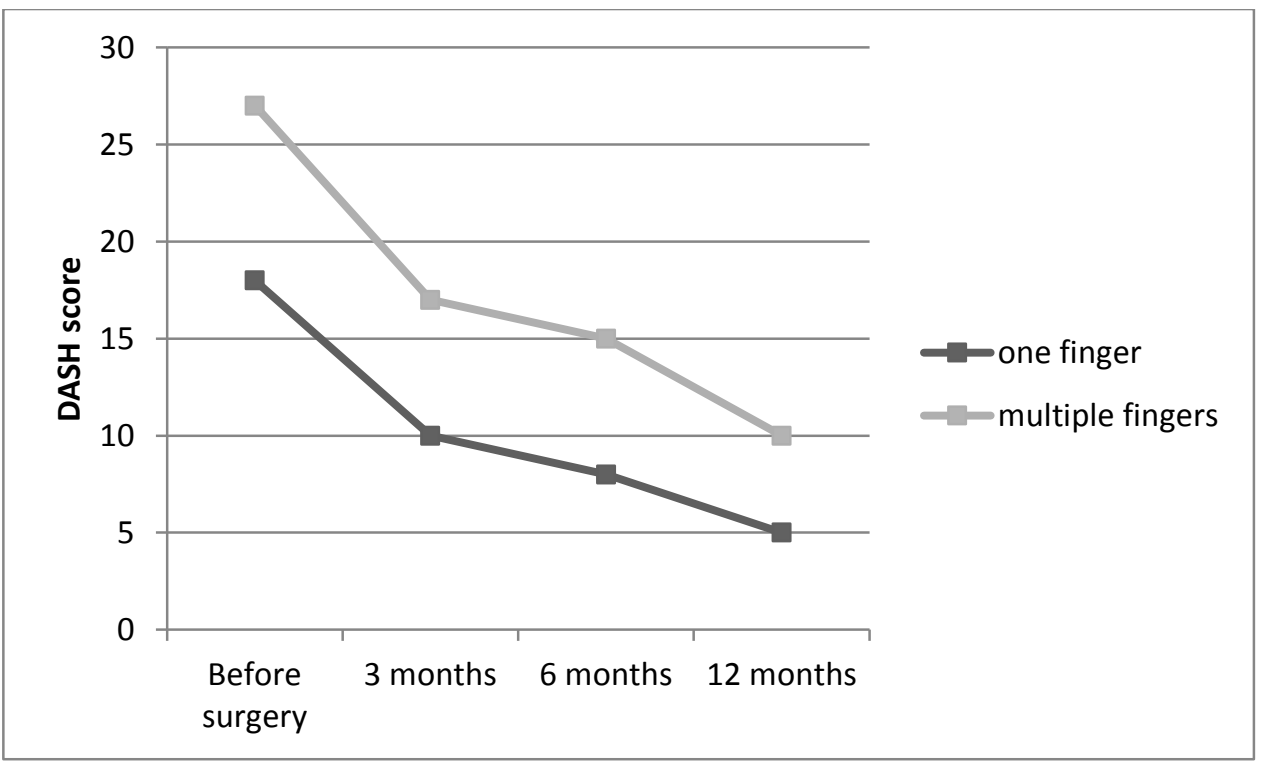

Figure 6. Outcomes on DASH score for subgroups consisting of patients with one operated finger $(\mathrm{n}=53)$ and multiple operated fingers $(\mathrm{n}=17)(P<.05)$. Data presented as mean DASH score. Rating scale: $0=$ no disability, $100=$ severest disability. 


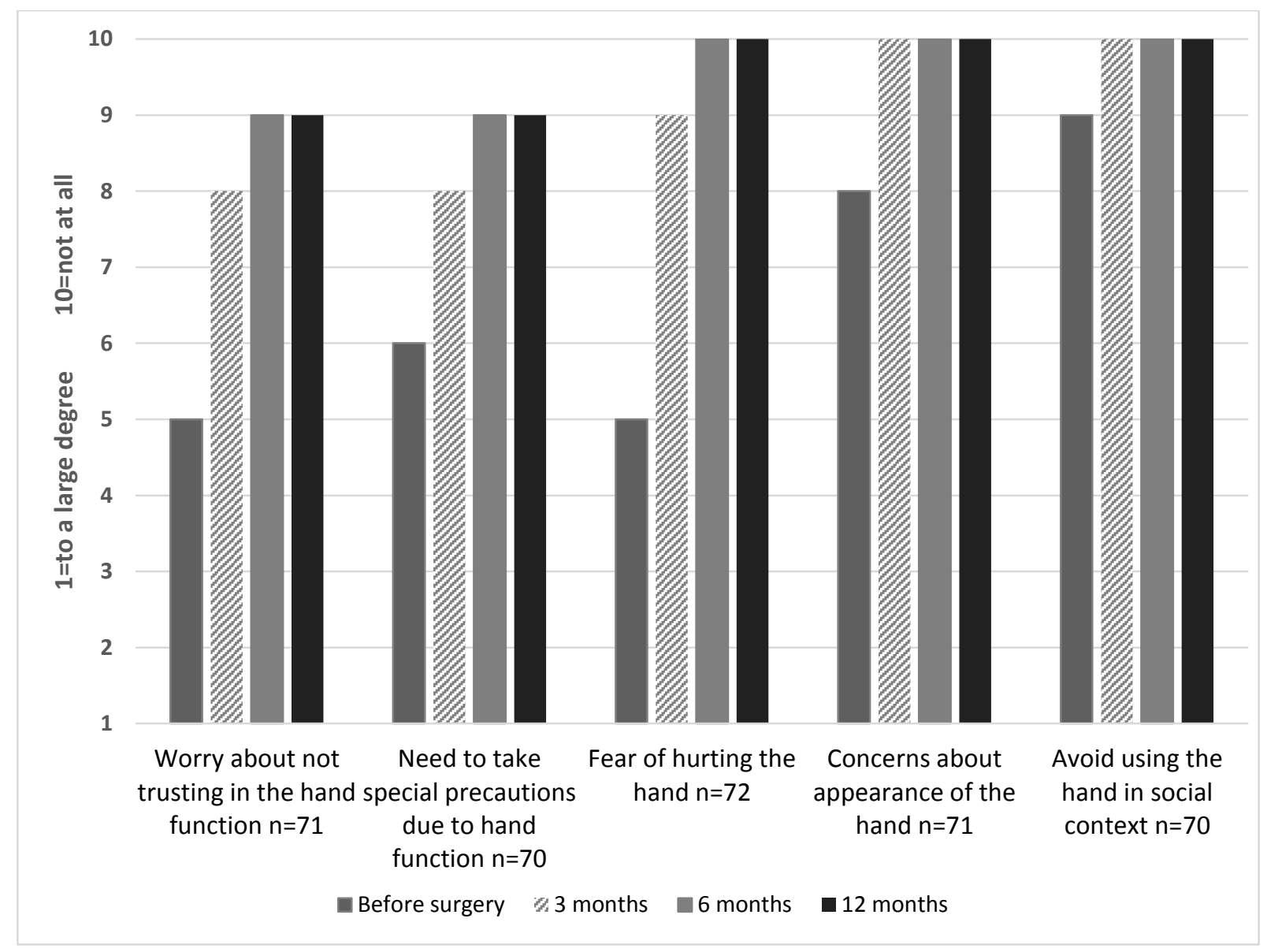

Figure 7. Outcomes on safety and social issues of hand function for patients attending all follow-ups $(P<.001)$. Data presented as median scores for the whole group. Rating scale: $1=$ to a large degree $10=$ not at all. 


\begin{tabular}{|c|c|c|c|c|}
\hline & & 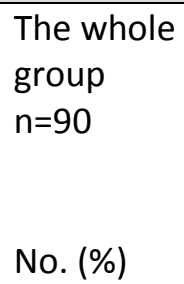 & $\begin{array}{l}\text { Patients with } \\
\text { surgery on one } \\
\text { finger } \\
n=70 \\
\text { No. (\%) }\end{array}$ & $\begin{array}{l}\text { Patients with } \\
\text { surgery on } \\
\text { multiple } \\
\text { fingers } \\
n=20 \\
\text { No. (\%) }\end{array}$ \\
\hline \multicolumn{5}{|l|}{ Background data } \\
\hline Sex & male (\%) & $77(85)$ & $61(87)$ & $16(80)$ \\
\hline Age & $\mathrm{m}(\mathrm{SD})$ & $68( \pm 9)$ & $68( \pm 9)$ & $69( \pm 9)$ \\
\hline Diabetes & yes (\%) & $10(11)$ & $6(9)$ & $4(20)$ \\
\hline Smoking & yes $(\%)$ & $8(9)$ & $5(7)$ & $3(15)$ \\
\hline \multirow[t]{3}{*}{ Heredity } & yes (\%) & $41(46)$ & $30(43)$ & $11(55)$ \\
\hline & no $(\%)$ & $18(20)$ & $15(21)$ & $3(15)$ \\
\hline & unknown (\%) & $31(34)$ & $25(36)$ & $6(30)$ \\
\hline Previous upper extremity & & $n=88$ & $n=69$ & $n=19$ \\
\hline disease(s) & Yes (\%) & $20(23)$ & $13(19)$ & $7(37)$ \\
\hline \multicolumn{5}{|l|}{ Severity of DD } \\
\hline \multirow[t]{4}{*}{ Disease duration $^{1}$} & $0-5$ years $(\%)$ & $22(24)$ & $19(27)$ & $3(15)$ \\
\hline & $6-10$ years $(\%)$ & $32(36$ & $28(40)$ & $4(20)$ \\
\hline & $11-15$ years (\%) & $17(19)$ & $12(17)$ & $5(25)$ \\
\hline & > 15 years $(\%)$ & $19(21)$ & $11(16)$ & $8(40)$ \\
\hline Dupuytren disease $(D D)^{1}$ & bilateral (\%) & $64(71)$ & $46(66)$ & $18(90)$ \\
\hline \multirow[t]{5}{*}{ Previous surgery for $D D$} & & $n=85$ & $n=65$ & $n=20$ \\
\hline & No $(\%)$ & $54(64)$ & $46(71)$ & $8(40)$ \\
\hline & Yes, other hand (\%) & $19(22)$ & $11(17)$ & $8(40)$ \\
\hline & $\begin{array}{l}\text { Yes, same hand but } \\
\text { other finger }(\%)\end{array}$ & $3(3)$ & $2(3)$ & $1(5)$ \\
\hline & $\begin{array}{l}\text { Yes, same hand \& } \\
\text { finger }(\%)\end{array}$ & $9(11)$ & $6(9)$ & $3(15)$ \\
\hline
\end{tabular}

\begin{tabular}{|c|c|c|c|c|}
\hline \multicolumn{5}{|l|}{ Intervention } \\
\hline \multirow{3}{*}{ Type of surgery } & Fasciectomy (\%) & $73(81)$ & $60(85)$ & $13(65)$ \\
\hline & + Open palm (\%) & $8(9)$ & $4(6)$ & $4(20)$ \\
\hline & + Volar release (\%) & $9(10)$ & $6(9)$ & $3(15)$ \\
\hline \multirow{2}{*}{$\begin{array}{l}\text { Complications during } \\
\text { surgery }\end{array}$} & Nerve injury (\%) & $4(4)$ & $3(4)$ & $1(5)$ \\
\hline & Blood vessel injury(\%) & $1(1)$ & 0 & $1(5)$ \\
\hline \multirow[t]{2}{*}{ Complications after surgery } & $\operatorname{CRPS}^{2}(\%)$ & $4(4)$ & $3(4)$ & $1(5)$ \\
\hline & Infection (\%) & $6(7)$ & $6(9)$ & 0 \\
\hline Surgery in dominant hand & Yes (\%) & $49(54)$ & $40(57)$ & $9(45)$ \\
\hline
\end{tabular}


Operated fingers

$\begin{array}{llll} & \mathrm{n}=114 & \mathrm{n}=70 & \mathrm{n}=44 \\ \text { Index } & 1(1) & 0(0) & 1(2) \\ \text { Long } & 9(8) & 1(1) & 8(18) \\ \text { Ring } & 34(30) & 15(21) & 19(43) \\ \text { Small } & 70(61) & 54(77) & 16(36)\end{array}$

${ }^{1}$ Significant difference between subgroups $p<0.05$

${ }^{2}$ CRPS, complex regional pain syndrome 
Table 2. Postoperative treatment, given in addition to standard protocol, based on individual needs during the first three months. Interventions were directed towards ROM, swelling, pain or scarring and are presented as numbers and proportions (\%) of patients attending three months follow-up ( $n=86)$.

Type of problem and intervention

No. (\%)

ROM

Dynamic finger extension splint

Dynamic finger flexion splint

$4(5)$

\section{Swelling}

Compression gloves or finger wrapping

$26(30)$

Pain

Transcutaneous electrical nerve stimulation (TENS)/acupuncture

Pain medication (Diclofenac and Paracetamol)

$13(15)$

\section{Scarring}

Zinc tape or occlusive materials

$10(12)$ 
Table 3. Outcomes on rating of scar pliability (firm, ropes or contracture), patients reaching a functional ROM and self-reported outcomes on expectations, recovery and satisfaction with hand function for patients attending all follow-ups ( $\mathrm{n}=77$ ). Data is presented as proportions (\%) and for scar pliability as risk ratio and $95 \%$ confidence intervals.

Before 3 months 6 months 12 months

surgery

\section{Scar pliability rated as firm, ropes or contractures:}

One operated finger $(n=57), \%$

Multiple operated fingers $(n=20), \%$

Risk Ratio, 95\% Cl
28

50

1.78

$0.97-3.26$
18

40

$2.28^{1}$

$4.75^{1}$

\section{Functional ROM, $(\mathrm{n}=77)$ :}

Patients reaching $\geq 165^{\circ} \mathrm{ROM}, \%$

20

81

84

\section{Expectations before surgery, $(n=74)$ :}

Expect hand function to be "fully recovered" , \%

Expect hand function to be "much better", \%

\section{Self-reported recovery of hand function, $(n=74)$ :}

Hand function "fully recovered", \%

Hand function "much better", \%
18

60
32

60

\section{Satisfaction with present hand function, $(n=75)$ :}

"Delighted" or "pleased" with current hand function, \%

4

$65^{2}$

$73^{3}$

${ }^{1}$ Significant increased risk of worse scar pliability for patients with surgery on several fingers, $p<0.05$

${ }^{2}$ Significant difference compared to before surgery, $p \leq 0.05$

${ }^{3}$ Significant difference compared to 3-month follow-up $p<0.05$ 
Table 4. Outcomes on disability (DASH score) and quality of life (EQ-5D), for patients attending all follow-up occasions. The DASH score, EQ-5D index and EQ-5D VAS are presented as mean and $95 \%$ confidence intervals.

\begin{tabular}{|c|c|c|c|c|}
\hline & Preoperative & 3 months & 6 months & 12 months \\
\hline DASH score, $(n=70)$ & $20(17-23)$ & $12(9-15)^{1}$ & $9(7-12)^{1}$ & $7(5-8)^{1}$ \\
\hline One operated finger $(n=53)$ & $18(15-22)^{2}$ & $10(6-13)^{2}$ & $8(5-10)^{2}$ & $5(3-8)^{2}$ \\
\hline Multiple operated fingers $(n=17)$ & $27(21-33)$ & $17(11-23)$ & $15(10-20)$ & $10(6-1)$ \\
\hline EQ-5D index, $(n=68)$ & $0.82(0.79-0.85)$ & $0.88(0.84-0.91)$ & $0.87(0.84-0.90)$ & $0.91(0.88-0.95)$ \\
\hline One operated finger $(n=52)$ & $0.81(0.78-0.85)$ & $0.89(0.85-0.94)$ & $0.89(0.85-0.92)$ & $0.93(0.89-0.97)^{2}$ \\
\hline Multiple operated fingers $(n=16)$ & $0.85(0.79-0.91)$ & $0.82(0.75-0.90)$ & $0.82(0.76-0.88)$ & $0.85(0.78-0.92)$ \\
\hline EQ-5D VAS, $(n=67)$ & $80(76-83)$ & $80(76-84)$ & $83(79-87)$ & $84(80-88)^{1}$ \\
\hline
\end{tabular}

\footnotetext{
${ }^{1}$ Significant difference compared to before surgery $p<0.05$

${ }^{2}$ Significant difference between subgroups $p<0.05$

Rating scales: DASH score $0=$ no disability $100=$ severest disability. EQ-5D index $1=$ full health, $-0.594=$ worst imaginable health state. EQ-5D VAS $100=$ best imaginable health state $0=$ worst imaginable health state.
} 


\begin{tabular}{|c|c|c|c|c|}
\hline & Before & 3 months & 6 months & 12 months \\
\hline & surgery & & & \\
\hline \multirow[t]{2}{*}{ MCP* extension, $\mathrm{m}(\mathrm{SD}), 95 \% \mathrm{Cl}$} & $51(25)$ & $7(9)^{1}$ & $5(8)^{1}$ & $5(9)^{1}$ \\
\hline & $45-57$ & $5-9$ & $3-7$ & $3-7$ \\
\hline \multirow[t]{2}{*}{ PIP* extension, $\mathrm{m}(\mathrm{SD}), 95 \% \mathrm{Cl}$} & $52(25)$ & $22(15)^{1}$ & $21(16)^{1}$ & $22(18)^{1}$ \\
\hline & $46-57$ & $19-25$ & $18-25$ & $17-26$ \\
\hline \multirow[t]{2}{*}{ DIP* extension, $\mathrm{m}(\mathrm{SD}), 95 \% \mathrm{Cl}$} & $8(14)$ & $2(7)^{1}$ & $2(7)^{1}$ & $4(8)^{1}$ \\
\hline & $4-11$ & $1-4$ & $1-4$ & $2-6$ \\
\hline \multirow[t]{2}{*}{ Total active extension deficit, $\mathrm{m}(\mathrm{SD}), 95 \% \mathrm{Cl}$} & $110(31)$ & $31(19)^{1}$ & $29(20)^{1}$ & $30(24)^{1}$ \\
\hline & $103-117$ & $27-36$ & $25-34$ & $25-36$ \\
\hline \multirow[t]{2}{*}{ MCP flexion, $\mathrm{m}(\mathrm{SD}), 95 \% \mathrm{Cl}$} & $90(7)$ & $84(8)^{1}$ & $87(7)^{1}$ & $89(8)$ \\
\hline & $88-91$ & $82-86$ & $86-89$ & $87-91$ \\
\hline \multirow[t]{2}{*}{ PIP flexion, $\mathrm{m}(\mathrm{SD}), 95 \% \mathrm{Cl}$} & $94(8)$ & $85(10)^{1}$ & $89(9)^{1}$ & $92(10)^{1}$ \\
\hline & $92-96$ & $83-87$ & $87-91$ & $90-94$ \\
\hline \multirow[t]{2}{*}{ DIP flexion, $m(S D), 95 \% C l$} & $56(14)$ & $53(15)$ & $54(16)$ & $55(16)$ \\
\hline & $53-59$ & $49-56$ & $50-57$ & $51-58$ \\
\hline \multirow[t]{2}{*}{ Total active finger flexion, $\mathrm{m}(\mathrm{SD}), 95 \% \mathrm{Cl}$} & $240(15)$ & $222(26)^{1}$ & $230(23)^{1}$ & $235(22)^{1}$ \\
\hline & $236-243$ & $216-228$ & $225-235$ & $230-240$ \\
\hline \multirow[t]{2}{*}{ Total range of motion, $\mathrm{m}(\mathrm{SD}), 95 \% \mathrm{Cl}$} & $129(34)$ & $190(38)^{1}$ & $201(36)^{1}$ & $205(36)^{1}$ \\
\hline & $122-137$ & 182-199 & $193-210$ & $197-213$ \\
\hline
\end{tabular}


Appendix B. Outcomes on safety and social issues for patients attending all follow-up occasions, presented as median (md) and interquartile range (lqr).

Preoperative 3 months 6 months 12 months

Worry about not trusting the

$5(3-7) \quad 8(6-10)^{1} \quad 9(8-10)^{1} \quad 9(7-10)^{1}$

hand function, md (Iqr), ( $n=71$ )

Need to take special precautions

$6(4-8) \quad 8(5-10)^{1} \quad 9(8-10)^{1} \quad 9(7-10)^{1}$

due to hand function, md (Iqr),

$(n=70)$

Fear of hurting the hand, md

$5(4-8)$

$9(7-10)^{1}$

$10(8-10)^{1}$

$10(8-10)^{1}$

(Iqr), ( $n=72)$

Concerns about the appearance of the hand, md (Iqr), ( $n=71)$

$8(5-9)$

$10(10-10)^{1}$

$10(10-10)^{1}$

$10(10-10)^{1}$

Avoidance of using of the hand in $9(5-10)$

$10(10-10)^{1}$

$10(10-10)^{1}$

$10(10-10)^{1}$ social contexts, $\mathrm{md}$ (Iqr), ( $\mathrm{n}=70)$

${ }^{1}$ Significant difference compared to before surgery $p<0.05$

Rating scale: $1=$ to a large degree $10=$ not at all. 
Appendix C. Model summary of the main effect of repeated measures ANOVA and interaction effect between number of operated fingers and change from before surgery to each follow up occasion in range of motion outcomes ( $n=77)$, DASH ( $n=70)$, EQ-5D VAS ( $n=67)$ and EQ-5D index ( $n=68)$.

\begin{tabular}{|c|c|c|c|c|c|}
\hline & df $1^{1}$ & $\mathbf{d f 2}^{1}$ & $\mathbf{F}$ & Sig & Partial $\eta^{2}$ \\
\hline Total active extension deficit & 1.58 & 118.51 & 425.26 & 0.000 & .850 \\
\hline Interaction effect of number of operated fingers & 1.58 & 118.51 & 1.51 & 0.227 & .020 \\
\hline MCP extension & 1.20 & 91.23 & 258.35 & 0.000 & .773 \\
\hline PIP extension & 1.39 & 105.37 & 144.48 & 0.000 & .655 \\
\hline DIP extension & 1.71 & 129.87 & 12.90 & 0.000 & .145 \\
\hline Total active finger flexion & 1.89 & 141.85 & 22.54 & 0.000 & .231 \\
\hline Interaction effect of number of operated fingers & 1.89 & 141.85 & 1.20 & 0.302 & .016 \\
\hline MCP flexion & 2.01 & 152.68 & 22.34 & 0.000 & .227 \\
\hline PIP flexion & 2.06 & 156.55 & 39.76 & 0.000 & .343 \\
\hline DIP flexion & 1.92 & 145.70 & 2.05 & 0.134 & .026 \\
\hline Total ROM & 1.75 & 131.06 & 170.58 & 0.000 & .695 \\
\hline Interaction effect of number of operated fingers & 1.75 & 131.06 & 0.312 & 0.703 & .004 \\
\hline DASH & 2.16 & 146.89 & 32.75 & 0.000 & .325 \\
\hline Interaction effect of number of operated fingers & 2.16 & 146.89 & 0.66 & 0.531 & .010 \\
\hline EQ-5D index & 2.72 & 179.69 & 2.45 & 0.071 & .036 \\
\hline Interaction effect of number of operated fingers & 2.72 & 179.69 & 2.81 & 0.046 & .041 \\
\hline EQ-5D VAS & 2.53 & 164.49 & 3.44 & 0.024 & .050 \\
\hline Interaction effect of number of operated fingers & 2.53 & 164.49 & 0.16 & 0.897 & .002 \\
\hline
\end{tabular}


